\title{
EDITORIAL - ARQUIVOLOGIA
}

Os novos modos de produção, uso e preservação da informação e os desafios políticos e científicos que estes impõem à sociedade e ao Estado são marcas do complexo cenário contemporâneo. Nesse quadro histórico, a Arquivologia talvez vivencie hoje um momento tão relevante quanto o da sua institucionalização no século XIX e sua reconfiguração a partir da metade do século passado.

Em países como o Brasil, historicamente à margem das grandes matrizes de pensamento e práticas arquivísticas, constatamos ainda hoje a justaposição desses momentos. Lidamos com dificuldades típicas de arquivos do século XIX, buscamos a adoção de padrões de gestão de documentos desenhados após a II Guerra Mundial e nos confrontamos com as possibilidades e problemas, cotidianamente renovadas, oferecidas pelas tecnologias da informação e da comunicação.

No Brasil, se há evidências de crescimento significativo na produção do conhecimento arquivístico nos últimos anos, ainda são ostensivas as lacunas na sua difusão. Contamos com mais teses, dissertações, pesquisas e congressos, paralelamente a uma ampliação significativa dos cursos de graduação em Arquivologia. Supõe-se, portanto, que a demanda por conhecimento arquivístico, nessa nova realidade, seja crescente. Essa produção é fundamental para ampliarmos os instrumentos teóricos e metodológicos que respaldem a adequada intervenção do arquivista num universo empírico cada vez mais complexo.

Além desses aspectos, no momento em que a Universidade Federal de Santa Catarina assume a criação do Curso de Graduação em Arquivologia, por iniciativa do Departamento de Ciência da Informação, parece-nos muito oportuno que a Encontros Bibli - Revista Eletrônica de Biblioteconomia e Ciência da Informação dedique um número especial à Arquivologia.

Motivados pelos editores da Encontros Bibli, mobilizamos colegas que gentilmente atenderam ao nosso convite e contribuíram com artigos para este número especial.

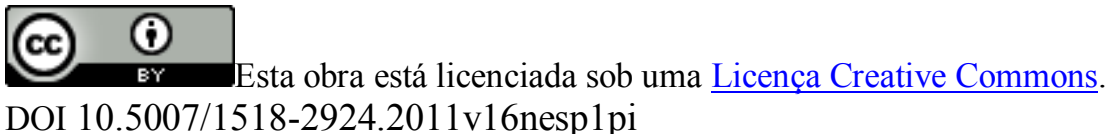

DOI 10.5007/1518-2924.2011v16nesp1pi 
Convidamos um conjunto de autores que, pela sua diversidade de interesses e inserção institucional, poderiam oferecer ao público interessado reflexões sobre alguns temas de interesse arquivístico. Ao lado de profissionais com carreira consolidada no campo, buscamos viabilizar a participação de arquivistas que estão em construção do seu percurso profissional, aventurando-se pela pós-graduação.

A Profa. Angélica Marques, do Curso de Arquivologia da Universidade de Brasília (UnB), oferece-nos um rico estudo sobre temáticas arquivísticas na Ciência da Informação. Diretora do TEAM Brasil no Projeto de pesquisa internacional InterPARES 3, Claudia Lacombe, do Arquivo Nacional, apresenta-nos reflexões sobre a complexa tarefa de tradução do Glossário multilíngue do Projeto InterPARES 3. A Profa. Anna Carla Almeida Mariz, do Curso de Arquivologia da Universidade Federal do Estado do Rio de Janeiro (UNIRIO), convida-nos ao debate sobre parâmetros para análise de sites de instituições arquivísticas sob a perspectiva da transferência da informação no ambiente da internet e suas demandas ao arquivista. Claudio Muniz Viana, arquivista da Universidade Federal do Estado do Rio de Janeiro (UFRJ), aborda um tema de interesse crescente, os arquivos de arquitetura, a partir da experiência do Núcleo de Pesquisa e Documentação da Faculdade de Arquitetura e Urbanismo da UFRJ. Arquivista da FIOCRUZ, Rose Tenório de Oliveira, apresenta-nos várias correlações entre a inexistência de políticas arquivísticas e a preservação de acervos documentais. O uso da microfilmagem e da digitalização para a preservação e acesso de documentos arquivísticos num contexto de opções tecnológicas à disposição dos arquivistas é contemplado com profundidade pelo Prof. Sérgio Conde de Albite Silva, do Curso de Arquivologia da Universidade Federal do Estado do Rio de Janeiro (UNIRIO). As professoras Eliana Maria dos Santos Bahia e Ursula Blattmann, do Departamento de Ciência da Informação da Universidade Federal de Santa Catarina (UFSC), juntamente com o Professor Raimundo Nonato Macedo dos Santos, do Departamento de Ciência da Informação da Universidade Federal de Pernambuco (UFPE), oferecem-nos interessantes resultados de um estudo bibliométrico da produção científica no campo da preservação digital. 
A todos esses colegas e à Equipe Editorial da Revista Encontros Bibli, os nossos profundos agradecimentos. Esperamos que os leitores do campo de Arquivologia e áreas afins possam desfrutar deste número Especial.

$\begin{array}{cc}\text { José Maria Jardim } & \begin{array}{c}\text { Renata Silva Borges } \\ \text { Editor }\end{array} \\ \text { Coeditora }\end{array}$

